\title{
Regulation of acute cortisol synthesis by cAMP-dependent protein kinase and protein kinase $C$ in a teleost species, the rainbow trout (Oncorhynchus mykiss)
}

\author{
M Lacroix and A Hontela \\ Département des Sciences Biologiques, Université du Québec à Montréal, TOXEN Research Center, Canada \\ (Requests for offprints should be addressed to A Hontela, Département des Sciences Biologiques, Université du Québec à Montréal, TOXEN Research Center, \\ C.P. 8888, succ. Centre-Ville, Montréal, Québec, Canada H3C 3P8; Email: hontela.alice@uqam.ca)
}

\begin{abstract}
The effects of cAMP-dependent protein kinase (PKA) and protein kinase $\mathrm{C}$ (PKC) on acute ACTH-stimulated cortisol secretion were assessed using a specific PKA inhibitor (H-89) and a PKC activator (phorbol 12myristate 13-acetate, PMA) in dispersed head kidney cells of rainbow trout (Oncorhynchus mykiss). To investigate the sites of action of both PKA and PKC, pregnenolone (a cortisol precursor stemmed from the rate limiting step in cortisol synthesis) and 25-OH-cholesterol (an exogenous substrate that bypasses the rate limiting step) were used as substrates, with and without ACTH stimulation. Inhibition of PKA decreased ACTH-stimulated cortisol secretion while activation of PKC had the same effect,
\end{abstract}

demonstrating that PKA stimulates and PKC inhibits cortisol synthesis. Inhibition of PKA and activation of PKC had no significant effect on pregnenolone-stimulated cortisol synthesis, indicating that both PKA and PKC act upstream from the pregnenolone step. Inhibition of PKA and activation of PKC had no significant effect on basal cortisol secretion in the presence of 25-OH-cholesterol, suggesting that PKA and PKC exert their effects on the mitochondrial cholesterol translocation step. This study provided evidence for the stimulatory role of PKA and the inhibitory role of PKC in the signalling pathways leading to cortisol synthesis in teleosts.

Journal of Endocrinology (2001) 169, 71-78

\section{Introduction}

Cortisol is the main steroid hormone produced in the interrenal tissue of teleost fish, the tissue homologous to the mammalian adrenal. It plays an important role in maintaining physiological homeostasis through effects on glycaemia, growth, and osmoregulation (Hontela 1997, Wendelaar Bonga 1997). Toxicological studies have demonstrated the disruptive effects of xenobiotics on adrenal steroidogenesis in teleosts (Ilan \& Yaron 1983, Brodeur et al. 1998, Hontela 1998) as well as in birds and mammals (Jönsson et al. 1993, 1994, Lund 1994, Mgbonyebi et al. 1994). It has also been reported that acute $(60 \mathrm{~min})$ non cytotoxic in vitro exposures of interrenal cells to $o, p^{\prime}-$ DDD, a DDT metabolite, inhibit cortisol secretion through effects prior to cAMP formation while heavy metals such as cadmium, zinc, and mercury seem to exert their effects downstream from cAMP production in the signalling cascade leading to acute cortisol synthesis (Leblond \& Hontela 1999, Benguira \& Hontela 2000). These studies have shown that xenobiotics may target different intracellular steps of adrenal steroidogenesis, some of which are relevant to the intracellular signalling pathways leading to cortisol synthesis.
The understanding of the pathways and intracellular messengers that regulate cortisol synthesis in fish is limited. Among studies on the control of cortisol synthesis by adrenocorticotrophin (ACTH), Patiño et al. (1986) demonstrated the importance of cAMP as an intracellular second messenger in the stimulation of cortisol production in the coho salmon (Oncorhynchus kisutch). Furthermore, dibutyryl-cAMP (dbcAMP) has been shown to stimulate cortisol secretion in a dose-related manner independently of ACTH in rainbow trout dispersed interrenal cells (Leblond et al. 2001). Mammalian studies had already reported that the main pathway leading to corticosteroid synthesis in the adrenal gland involves ACTH which stimulates a signalling cascade integrating G-proteins, adenylyl cyclase, cAMP and protein kinase A (PKA) (Miller 1988, Schimmer 1995). Other pathways involving protein kinase $\mathrm{C}(\mathrm{PKC})$ via stimulation by angiotensin II (AII) or acetylcholine, both known secretagogues of cortisol in fish (Perrott \& Balment 1990, Kloas et al. 1994), at least share a role in the regulation of corticosteroid synthesis, both chronic and acute (Bird et al. 1990).

The chronic regulation of transcription factors and transcription of genes coding for proteins necessary for 
cortisol synthesis (i.e. CytP450 hydroxylases) by cAMP, PKA or PKC has been investigated in numerous mammalian models (Schimmer 1995). However, the time course of the disruptive effects reported in recent toxicological studies in fish (Leblond \& Hontela 1999, Benguira \& Hontela 2000) suggests that mechanisms regulating acute cortisol synthesis may be targeted by some adrenotoxicants. Acute trophic hormone-mediated steroidogenesis calls for rapid regulation mechanisms involving intracellular messengers such as PKA and PKC and proteins that act upon the rate limiting step in cortisol synthesis in the adrenal gland: the transfer of cholesterol to the inner mitochondrial membrane (Clark et al. 1994, Lin et al. 1995, Stocco \& Clark 1996).

Since the signalling pathways leading to cortisol synthesis have not been investigated in teleosts, the purposes of this study were (1) to characterize the roles of PKA and PKC in acute cortisol synthesis in the rainbow trout (Oncorhynchus mykiss) with the use of a specific PKA inhibitor, H-89 and a PKC activator, phorbol 12-myristate 13-acetate (PMA), and (2) to allocate specific sites of action for these intracellular messengers in their regulation of acute cortisol synthesis.

\section{Materials and Methods}

\section{Animals}

Male and female rainbow trout (mean weight 80-110 g) were bought from Labelle Piscicultures, Inc. (Labelle, Quebec, Canada). Fish were kept in freshwater flowthrough basins $(6001)$ maintained at $15 \pm 2{ }^{\circ} \mathrm{C}$, supplied with filtered and oxygen saturated water (hardness $\left.70 \mathrm{mg} / 1 \mathrm{CaCO}_{3}\right)$ at a rate of $3 \cdot 8 \mathrm{l} / \mathrm{min}$. They were fed daily with a commercial trout chow at the manufacturer's recommended rate $(10 \mathrm{~g} / \mathrm{kg}$ of fish). A two-week acclimation period was allowed before the beginning of the experiments.

\section{Chemicals}

Porcine adrenocorticotrophic hormone $\left(\mathrm{ACTH}_{1-39}\right)$, pregnenolone (3 $\beta$-hydroxy-5-pregne-20-one), MEM (minimal essential medium), BSA (bovine serum albumin), PMA, and 25-OH-cholesterol were obtained from Sigma-Aldrich (Oakville, Ontario, Canada). Collagenase/ dispase mixture (collagenase from Achromobacter iophagus and dispase from Bacillus polymyxa) was bought from Boehringer Mannheim (Laval, Quebec, Canada). H-89 (N-[2-(p-bromocinnamylamino)ethyl]-5-isoquinolinesulphonamide $2 \mathrm{HCl}$ ) was obtained from BIOMOL Research Laboratories (Plymouth Meeting, PA, USA). MS-222 ( $m$-aminobenzoic acid ethyl ester methanesulphonate) was bought from ICN Pharmaceuticals (Orangeburg, NY, USA). Other chemicals used were reactive grade. Pregnenolone and 25-OH-cholesterol were disolved in 100\% ethanol, PMA and $\mathrm{H}-89$ were dissolved in dimethylsulphoxide (DMSO). Concentrations of DMSO and ethanol in the final cell suspension medium were $5 \%(\mathrm{v} / \mathrm{v})$ and $2 \%(\mathrm{v} / \mathrm{v})$ respectively. These concentrations have no effect on cortisol secretion or cell viability (data not shown) (Leblond \& Hontela 1999).

\section{Cell suspensions}

The cell suspension method has been described elsewhere (Leblond et al. 2001). The head kidneys of 8-10 fish were used in each treatment, each head kidney being treated individually as $n=1$ replicate. Fish were anaesthetized in MS-222, bled from the caudal vasculature and perfused twice with a $30 \mathrm{ml}$ syringe containing a saline solution $(0.7 \% \mathrm{NaCl})$, to remove as much blood as possible. The head kidney was then dissected and placed in a tube containing MEM supplemented with $5 \mathrm{~g} / 1$ BSA and $2 \cdot 2 \mathrm{~g} / 1 \mathrm{NaHCO}_{3}, \mathrm{pH} 7 \cdot 4$ (complete medium). The tissue was washed twice with complete medium, resuspended in $2.5 \mathrm{ml}$ complete medium with $2.0 \mathrm{mg} / \mathrm{ml}$ collagenase/ dispase, and incubated in a $15 \mathrm{ml}$ conical tube for $60 \mathrm{~min}$ at room temperature with gentle agitation, resuspending the cells every 15 min with a transfer pipette. Following enzymatic digestion, the solution was filtered with a $30 \mu \mathrm{m}$ mesh cloth and the filtrate was centrifuged at $300 \times \mathbf{g}$ (1000 r.p.m.) for $5 \mathrm{~min}$. The supernatant was then removed, the pellet resuspended in $1.5 \mathrm{ml}$ complete medium and cellular density adjusted to $75 \times 10^{6}$ cells $/ \mathrm{ml}$ using a haemacytometer.

\section{In vitro effects of agonists and antagonists on cortisol secretion}

The cells were distributed in a 96-well microplate at $150 \mu \mathrm{l}$ of $75 \times 10^{6}$ cells $/ \mathrm{ml}$ per well and incubated under optimal conditions, as described previously (Leblond et al. 2001). In summary, a $2-\mathrm{h}$ preincubation at $15{ }^{\circ} \mathrm{C}$ (acclimation temperature of basins in which fish were held) with light agitation was necessary to reach basal cortisol secretion. Cells were then resuspended in complete medium and the microplate was centrifuged at $300 \times \mathbf{g}$ for $3 \mathrm{~min}$. The supernatants were then removed and the pellets were resuspended in $150 \mu \mathrm{l}$ complete medium containing the test agent(s). Depending on the experiment, the test agents were: the optimal dose of ACTH $\left(1 \mathrm{IU} / \mathrm{ml}\right.$ or $\left.2 \cdot 4 \times 10^{-6} \mathrm{M}\right)$ as previously investigated by Leblond et al. (2001) and various concentrations of 25-OH-cholesterol, pregnenolone, H-89 and PMA. Cells were then incubated at $15^{\circ} \mathrm{C}$ for $60 \mathrm{~min}$ with the test agents with light agitation and centrifuged one more time at $300 \times \mathbf{g}$ for $3 \mathrm{~min}$. The supernatants were collected and cortisol determined by RIA (ICN Pharmaceuticals). Blanks of every agent used in the assays (H-89, PMA, 25-OH-cholesterol and pregnenolone) revealed no cross-reactivity with the cortisol RIA used in the study (data not shown). Cell viability was assessed using Trypan Blue exclusion method. 

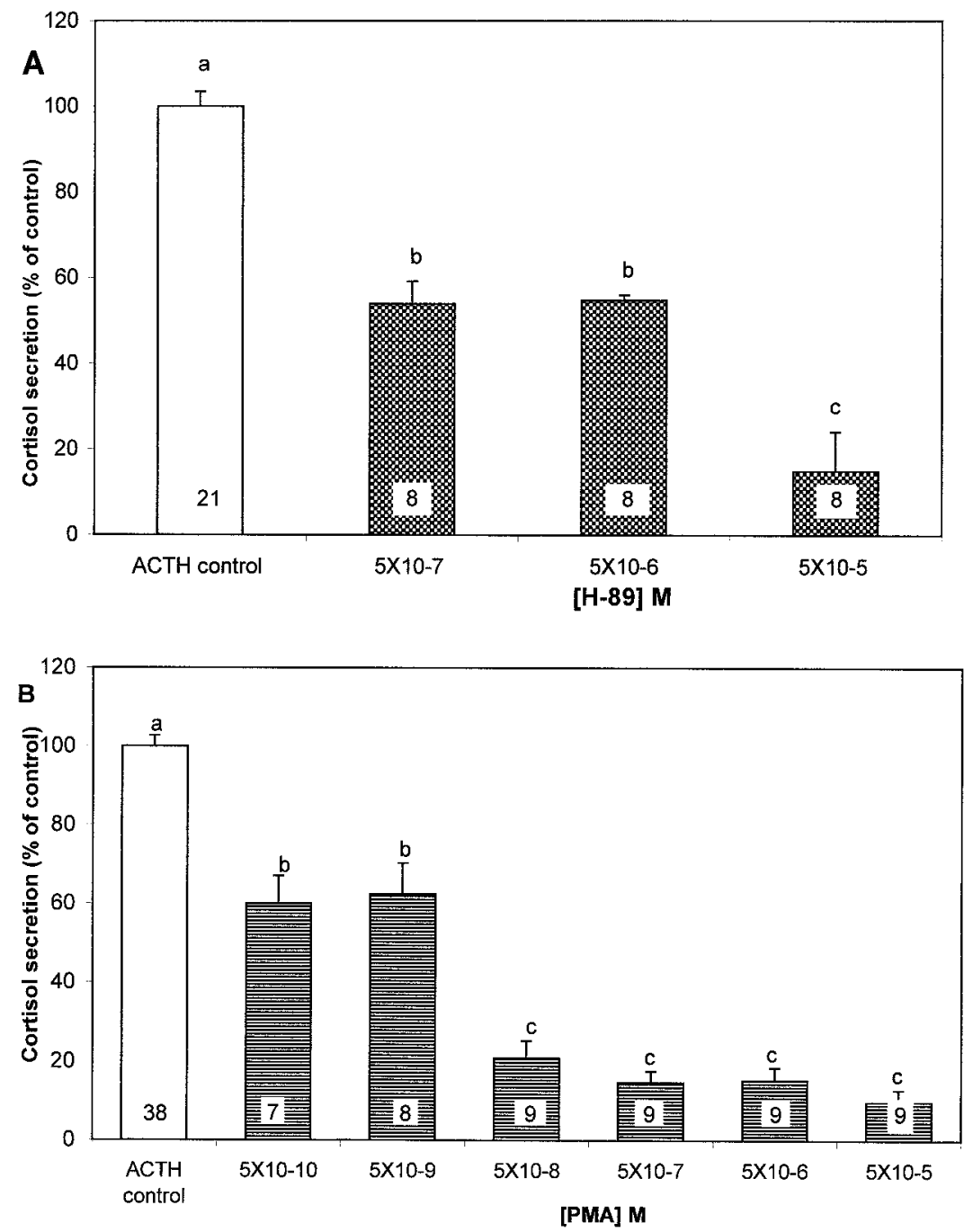

Figure 1 Effect of (A) PKA inhibitor H-89 and (B) PKC activator PMA on cortisol secretion of rainbow trout adrenocortical cells stimulated with ACTH $(1 \mathrm{IU} / \mathrm{ml})$, and incubated for $1 \mathrm{~h}$ at $15{ }^{\circ} \mathrm{C}$ (expressed as mean percentage of $\mathrm{ACTH}$-stimulated secretion used as positive control, \pm S.E.M.). Significant differences between treatments are represented by different letters (ANOVA and Tukey-Kramer HSD test, $\alpha=0 \cdot 05$ ). Cells obtained from the interrenal tissue of one fish correspond to $n=1$, numbers of replicates are indicated within each bar.

\section{Statistical analysis}

Statistical significance in each experiment was determined using a one-way analysis of variance (ANOVA) and a Tukey-Kramer Highly Significant Difference (HSD) test $(\alpha=0 \cdot 05)$. A value of $P<0 \cdot 05$ was considered significant.

\section{Results}

Effect of H-89 and PMA on ACTH-stimulated acute cortisol synthesis

To investigate the roles of both PKA and PKC in acute cortisol synthesis in rainbow trout, adrenocortical cells were incubated for $1 \mathrm{~h}$ with increasing concentrations $\left(5 \times 10^{-7}\right.$ to $\left.5 \times 10^{-5} \mathrm{M}\right)$ of $\mathrm{H}-89$, a PKA specific inhibitor (Fig. 1A), or increasing concentrations $\left(5 \times 10^{-10}\right.$ to $\left.5 \times 10^{-5} \mathrm{M}\right)$ of PMA, a PKC activator (Fig. 1B), and they were stimulated by $\mathrm{ACTH}$ $(1 \mathrm{IU} / \mathrm{ml})$. A dose-related decrease in ACTH-stimulated cortisol secretion was observed when cells were exposed to $\mathrm{H}-89$ or PMA. Concentrations of $5 \times 10^{-7} \mathrm{M}$ and $5 \times 10^{-10} \mathrm{M} \mathrm{H}-89$ and PMA respectively, significantly decreased cortisol secretion $(\approx 55 \%$ to $60 \%$ of control). The ACTH-stimulated cortisol secretion of untreated controls (ACTH only) was $18 \cdot 3 \pm 1 \cdot 8 \mathrm{ng} / \mathrm{ml}$ (mean \pm s.E.M, $n=38$, Fig. $1 \mathrm{~B}$ ). 

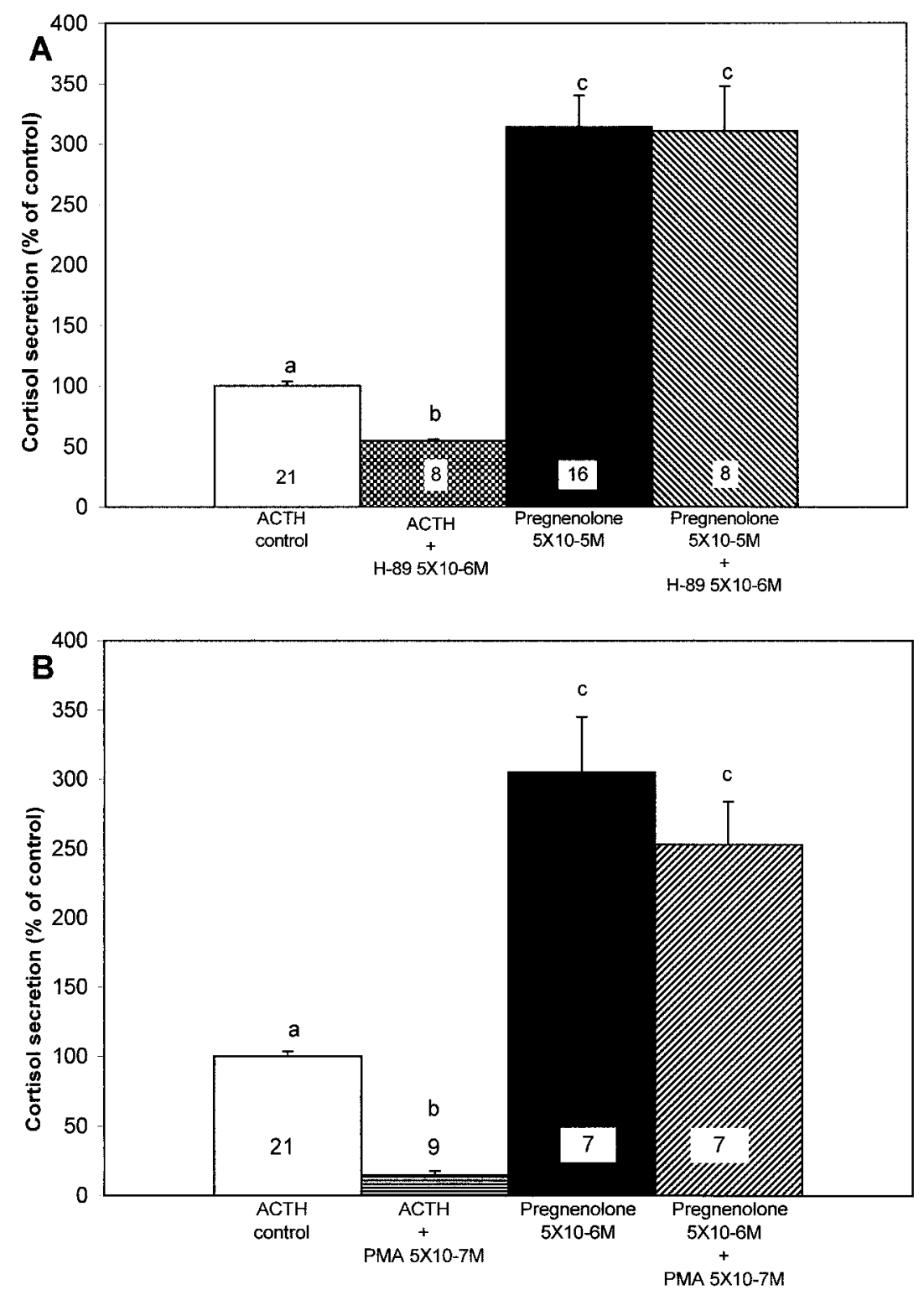

Figure 2 Effect of (A) PKA inhibitor $\mathrm{H}-89$ and (B) PKC activator PMA on cortisol secretion of rainbow trout adrenocortical cells stimulated with ACTH $(1 \mathrm{IU} / \mathrm{ml})$ or pregnenolone ( 5 and $50 \mu \mathrm{M}$ ), and incubated for $1 \mathrm{~h}$ at $15{ }^{\circ} \mathrm{C}$ (expressed as mean percentage of control, see Fig. 1 for details). Significant differences between treatments are represented by different letters (ANOVA and Tukey-Kramer HSD test, $\alpha=0 \cdot 05$ ).

Effect of H-89 and PMA downstream from the rate limiting step in acute cortisol synthesis

To identify the sites of action of both PKA and PKC in the signalling pathways leading to cortisol synthesis, pregnenolone (a cortisol precursor stemmed from the cholesterol side chain cleavage reaction immediately following the rate limiting step in cortisol synthesis) was used as a substrate. Pregnenolone produced a dose-related increase in cortisol secretion, concentrations of $5 \times 10^{-7} \mathrm{M}$, $5 \times 10^{-6} \mathrm{M}$ and $5 \times 10^{-5} \mathrm{M}$ pregnenolone produced respectively $100 \%, 305 \%$ and $315 \%$ of the optimal ACTH-induced cortisol secretion. Furthermore, there were no significant effects of either H-89 or PMA on cortisol secretion stimulated with pregnenolone, compared with ACTH-stimulated cortisol secretion (Fig. 2). 


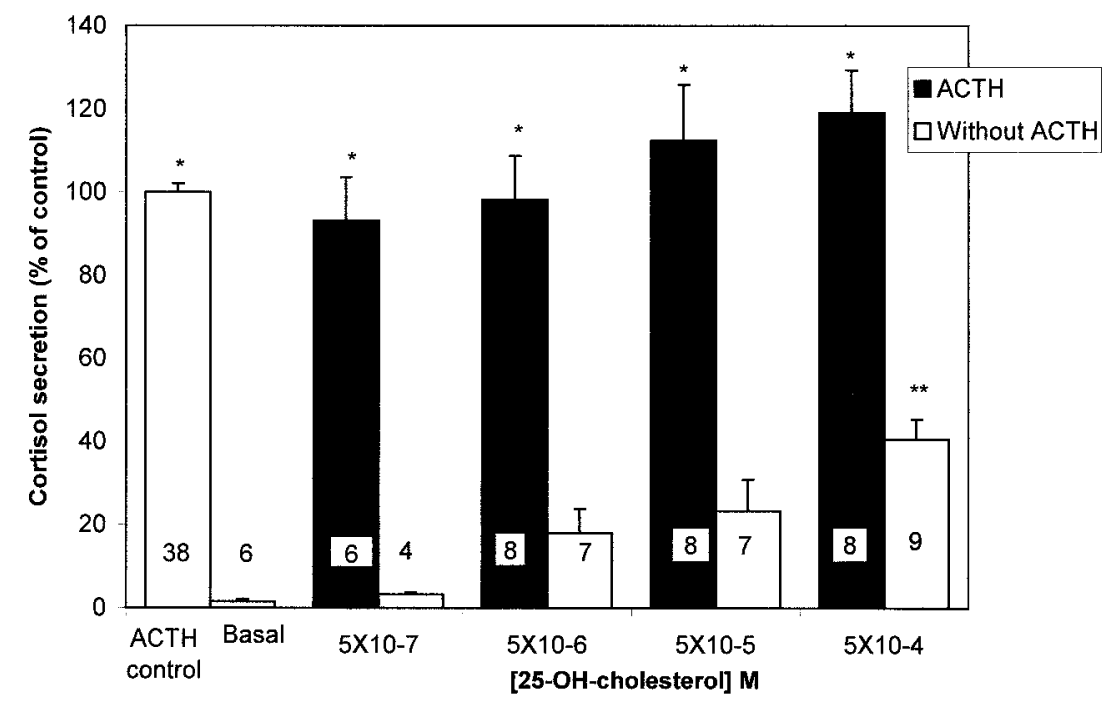

Figure 3 Effect of exogenous substrate 25-OH-cholesterol on cortisol secretion in ACTHstimulated and non-stimulated rainbow trout adrenocortical cells incubated for $1 \mathrm{~h}$ at $15{ }^{\circ} \mathrm{C}$ (expressed as mean percentage of control, see Fig. 1 for details). ${ }^{*}$ Significant difference from corresponding treatment without ACTH stimulation, and ${ }^{* *}$ significant difference from basal secretion without 25-OH-cholesterol (ANOVA and Tukey-Kramer HSD test, $\alpha=0 \cdot 05$ ).

Effect of H-89 and PMA on the rate limiting step in acute cortisol synthesis

To investigate the role of both PKA and PKC on the rate limiting step in cortisol synthesis, 25-OH-cholesterol (an exogenous substrate that bypasses the regulated endogenous cholesterol transport and translocation steps) was first tested on both ACTH-stimulated and basal cortisol secretion (without ACTH stimulation) (Fig. 3), as well as with both agents (H-89 and PMA) (Fig. 4). Figure 3

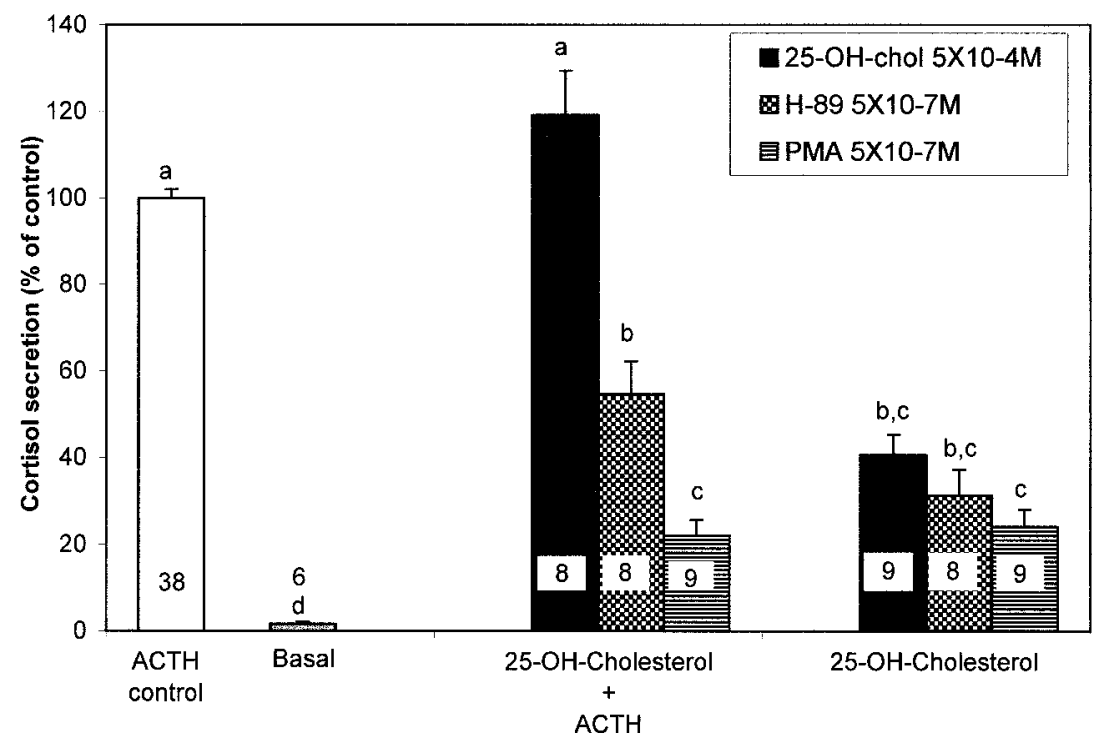

Figure 4 Effect of PKA inhibitor H-89 and PKC activator PMA on cortisol secretion with and without ACTH $(1 \mathrm{IU} / \mathrm{ml})$ stimulation in the presence of exogenous substrate $25-\mathrm{OH}$-cholesterol in rainbow trout adrenocortical cells incubated for $1 \mathrm{~h}$ at $15{ }^{\circ} \mathrm{C}$ (expressed in mean percentage of control, see Fig. 1 for details). Significant differences between treatments are represented by different letters (ANOVA and Tukey-Kramer HSD test, $\alpha=0 \cdot 05$ ). 
shows a dose-related increase in basal cortisol production for cells incubated with $25-\mathrm{OH}$-cholesterol with significant stimulation at a dose of $5 \times 10^{-4} \mathrm{M} 25-\mathrm{OH}-$ cholesterol. No significant effect was observed for the ACTH-stimulated cells incubated with the exogenous substrate compared with the control. When H-89 and PMA were added (Fig. 4) to the ACTH-stimulated cells, the results were as expected from the previous experiments (Figs 1 and 2). The inhibition of PKA by H-89 produced a significant $(50 \%)$ decrease in cortisol secretion while activation of PKC by PMA also decreased cortisol secretion to $20 \%$ of the control. However, H-89 and PMA had no significant effect on basal cortisol secretion in the presence of 25-OH-cholesterol, although their related cortisol secretion was significantly higher than basal values without the exogenous cholesterol substrate.

\section{Discussion}

Recent studies on fish adrenal function emphasized the need for a better understanding of the intracellular pathways responsible for the control of corticosteroidogenesis in fish in order to elucidate the mechanisms and identify the intracellular processes where endocrine modulators such as adrenotoxicants affect cortisol synthesis.

The first part of this study was designed to characterize the roles of PKA and PKC, implicated in the intracellular signalling pathways, in acute ACTH-mediated cortisol synthesis in a teleost fish, the rainbow trout. The use of the specific PKA inhibitor H-89 (Chijiwa et al. 1990) produced a dose-related decrease in cortisol production, indicating a stimulatory role of PKA in ACTH-mediated acute cortisol synthesis. Previous studies have demonstrated the important role of the ACTH-mediated signalling pathway in the stimulation of corticosteroidogenesis in mice (Schimmer 1995), bovine (Yoshida et al. 1993), and fish (Gupta et al. 1985) species. Our study implicates, for the first time, PKA as a crucial stimulatory component in the ACTH-mediated signalling pathway in fish adrenal steroidogenesis. Other studies using the same inhibitor (H-89) on fish ovarian follicular steroidogenesis have involved PKA in a similar cAMP-mediated pathway (Srivastava \& Van der Kraak 1994a,b).

The first part of our study also investigated the role of PKC, a constituent of a distinct signalling pathway which involves phosphoinositide turnover and diacylglycerol production via phospholipase C (PLC) activation (Berridge 1987, Berridge \& Irvine 1989). PLC activation by hormones such as AII, vasopressin and acetylcholine, and its effect on steroidogenesis have been extensively studied in mammals and the interactions between this signalling pathway and the cAMP-mediated pathway have proved to be highly species and cell-type specific (see review by Bird et al. 1990). The presence of AII and acetylcholine in fish (Wendelaar Bonga 1993) could imply similar regulation mechanisms of steroidogenesis. Our results show that PKC has an inhibitory role in the acute cortisol response in fish adrenocortical cells. Activation of PKC by a phorbol ester (PMA) caused a dose-dependent decrease in ACTH-stimulated acute cortisol synthesis. Studies using phorbol esters in human and bovine adrenal cells have shown that these PKC activators suppress cAMP-stimulated steroidogenesis (Mason et al. 1986, Naseeruddin \& Hornsby 1990). However, other studies demonstrated the opposite effects in bovine and mouse Y1 cells (Culty et al. 1984, Widmaier \& Hall 1985). Studies on fish ovarian follicular steroidogenesis revealed that activation of PKC by PMA has an inhibitory effect on trophically-stimulated steroidogenesis (Van der Kraak 1990, 1992). Our primary findings using H-89 and PMA indicate that acute steroidogenesis in the fish adrenal (interrenal) is under the control of at least two signalling pathways involving PKA and PKC.

The second objective of this study was to identify a specific site of action for both kinases (PKA and PKC) implicated in the control of ACTH-stimulated acute steroidogenesis in rainbow trout. Pregnenolone (product of the side chain cleavage reaction immediately following the rate limiting step of mitochondrial cholesterol translocation) was used as a substrate to determine whether PKA or PKC have effects downstream from the rate limiting step in cortisol synthesis. Our results show that neither inhibition of PKA by $\mathrm{H}-89$ nor activation of PKC by PMA have any effect on pregnenolone-stimulated cortisol secretion. These results call for regulation mechanisms that act prior to pregnenolone formation for both PKA and PKC. Furthermore, higher doses of pregnenolone (data not shown) produced massive production of cortisol revealing the high capacity of the seemingly unregulated steroidogenic enzymes located downstream of pregnenolone formation. These results provide further evidence for a rate limiting step upstream of pregnenolone formation that is regulated by both PKA and PKC.

Following the finding of the implication of both kinases upstream of pregnenolone formation, it was important to assess whether PKA and PKC exert their regulatory roles on the mitochondrial cholesterol translocation, believed to be the rate limiting step in the acute response (Privalle et al. 1983, Stocco \& Clark 1996, Kallen et al. 1998). An exogenous cholesterol substrate, 25-OH-cholesterol, which has the capacity to diffuse across the mitochondrial membranes (Toaff et al. 1982) was therefore used to stimulate acute cortisol synthesis while bypassing the translocation step. Our results show that 25-OHcholesterol did not affect ACTH-stimulated acute cortisol synthesis, providing evidence that ACTH stimulates intracellular responses that facilitate the conversion of endogenous cholesterol usually not available unless the signalling pathway is activated. However, in the absence of ACTH, 25-OH-cholesterol produced a dose-related 
increase in cortisol synthesis, indicating that 25-OHcholesterol effectively bypasses the rate limiting step and is therefore available for enzymatic catalysis. The lower values for basal secretion in the presence of $25-\mathrm{OH}-$ cholesterol could be attributed to lower conversion rates for the exogenous cholesterol substrate. Although 25-OHcholesterol is converted at a lower velocity than endogenous cholesterol in mitochondria of the human placenta and porcine ovaries (Tuckey \& Holland 1989, Tuckey 1992), other studies on mitochondria from the bovine adrenal, porcine testes, rat adrenal and rat ovaries have shown that 25-OH-cholesterol has a higher conversion rate than endogenous cholesterol (Mason \& Robidoux 1978, Tuckey \& Atkinson 1989). Conversion rates thus seem to be species and cell-type specific. The use of other hydroxylated forms of cholesterol could provide better substrates for side chain cleavage, which in turn might be of better use since doses used for the stimulation of steroidogenesis would be decreased. The PKA inhibitor H-89 and the PKC activator PMA had no significant effect on the cells incubated with 25-OH-cholesterol only (without ACTH). These results could imply that both kinases may regulate the rate limiting step in ACTHstimulated acute cortisol synthesis in rainbow trout interrenal cells. However, Van der Kraak (1992) has shown that PMA exerts its inhibitory effects both prior to and distal from cAMP formation in goldfish preovulatory ovarian follicles. Therefore, PKC might also exert its inhibitory effects by acting simultaneously on different steps in the steroidogenic pathway in fish adrenal steroidogenesis.

The proximity of the site of action of both PKA and PKC in the regulation of acute ACTH-mediated cortisol synthesis calls for further studies to evaluate their mechanism of action. The steroidogenic acute regulatory protein (StAR) characterized by Clark et al. (1994) is now recognized as the principal mediator of acute trophic hormone-stimulated steroidogenesis in mammals (Lin et al. 1995, Kallen et al. 1998). StAR protein can be phosphorylated by PKA and PKC (Hartigan et al. 1995, Arkane et al. 1997). Phosphorylation of StAR provides increased StAR activity (Arkane et al. 1997) and stimulation by the cAMP-PKA-mediated pathway causes rapid accumulation of StAR mRNA (Lehoux et al. 1998). Also, PKC has been shown to inhibit StAR mRNA production in porcine granulosa cells (Pescador et al. 1997). Investigations into the characterization of StAR protein in teleosts might provide valuable answers as to the mechanisms by which cortisol synthesis is regulated in fish.

In conclusion, this study provided evidence that both PKA and PKC have a role in the regulation of ACTH-stimulated acute cortisol synthesis in rainbow trout. Furthermore, our results show that PKA has a role in transducing the stimulation message initiated when ACTH binds to its receptor. On the other hand, PKC has a negative control on stimulated cortisol synthesis and effectively inhibits its production when activated.
Characterization of the specific sites of action of PKA and PKC has led us to believe that both kinases carry out their effects between the binding of the signalling molecule and the cholesterol side chain cleavage reaction, more precisely on the rate limiting mitochondrial cholesterol translocation step.

Further investigations will examine the roles of PKA and PKC in teleost adrenal steroidogenesis in relation to different xenobiotics known to impair cortisol synthesis. Characterization of the mechanisms of action of both PKA and PKC in these lower vertebrate species is also an important aspect to develop if we are to understand the complex processes that regulate acute adrenal steroidogenesis in fish.

\section{Acknowledgements}

We wish to thank M Bisson, V Leblond, A Lacroix and $\mathrm{H}$ Lévesque for valuable help during the study.

This study was funded by a grant from the Natural Sciences and Engineering Council of Canada (NSERC) to A Hontela and by an undergraduate bursary from the NSERC to M Lacroix.

\section{References}

Arkane F, King SR, Du Y, Kallen CB, Walsh LP, Watari H, Stocco DM \& Strauss III JF 1997 Phosphorylation of steroidogenic acute regulatory protein (StAR) modulates its steroidogenic activity. Journal of Biological Chemistry 272 32656-32662.

Benguira S \& Hontela H 2000 Adrenocorticotrophin- and cyclic adenosine $3^{\prime}, 5^{\prime}$-monophosphate-stimulated cortisol secretion in interrenal tissue of rainbow trout exposed in vitro to DDT compounds. Environmental Toxicology and Chemistry 19 842-847.

Berridge MJ 1987 Inositol triphosphate and diacylglycerol: two interacting second messengers. Annual Reviews of Biochemistry 56 159-193.

Berridge MJ \& Irvine RF 1989 Inositol phosphates and cell signalling. Nature 341 197-205.

Bird IM, Walker SW \& Williams BC 1990 Agonist-stimulated turnover of the phosphoinositides and the regulation of adrenocortical steroidogenesis. Journal of Molecular Endocrinology $\mathbf{5}$ 191-209.

Brodeur JC, Daniel C, Ricard AC \& Hontela A 1998 In vitro response to ACT. Aquatic Toxicology 42 103-113.

Chijiwa T, Mishima A, Hagiwara M, Sano M, Hayashi K, Inoue T, Naito K, Toshioka T \& Hidaka H 1990 Inhibition of forskolininduced neurite outgrowth and protein phosphorylation by a newly synthesized selective inhibitor of cyclic AMP-dependent protein kinase, N-[2-(p-bromocinnamylamino) ethyl]-5-

isoquinolinesulfonamide (H-89), of PC12D pheochromocytoma cells. Journal of Biological Chemistry 265 5267-5272.

Clark BJ, Wells J, King SR \& Stocco DM 1994 The purification, cloning, and expression of a novel luteinizing hormone-induced mitochondrial protein in MA-10 mouse leydig tumor cells. Characterization of the steroidogenic acute regulatory protein (StAR). Journal of Biological Chemistry 269 28314-28322.

Culty M, Vilgrain I \& Chambaz EM 1984 Steroidogenic properties of phorbol ester and $\mathrm{Ca}^{2+}$ ionophore in bovine adrenocortical cell suspensions. Biochemical and Biophysical Research Communications 121 1673-1681. 
Gupta OP, Lahlou B, Botella J \& Porthé-Nibelle J 1985 In vivo and in vitro studies on the release of cortisol from interrenal tissue in trout. I. Effects of ACTH and prostaglandins. Experimental Biology 43 201-212.

Hartigan JA, Green EG, Mortensen RM, Menachery A, Williams GH \& Orme-Johnson NR 1995 Comparison of protein phosphorylation patterns produced in adrenal cells by activation of cAMP-dependent protein kinase and Ca-dependent protein kinase. Journal of Steroid Biochemistry and Molecular Biology 53 95-101.

Hontela A 1997 Endocrine and physiological responses of fish to xenobiotics: role of glucocorticosteroid hormones. Reviews in Toxicology 1 1-46.

Hontela A 1998 Interrenal dysfunction in fish from contaminated sites: in vivo and in vitro assessment. Environmental Toxicology and Chemistry 17 44-48.

Ilan Z \& Yaron Z 1983 Interference of $o, p^{\prime}$-DDD with interrenal function and cortisol metabolism in Sarotherodon aureus (Steindachner). Journal of Fish Biology 22 657-669.

Jönsson CJ, Lund BO \& Brandt I 1993 Adrenocorticolytic DDT-metabolites: studies in mink Mustela vison, and otter Lutra lutra. Ecotoxicology 2 41-53.

Jönsson CJ, Lund BO \& Brandt I 1994 Toxicity and irreversible binding of two DDT metabolites - 3-methylsulfonyl-DDE and $o, p^{\prime}$-DDD - in adrenal interrenal cells in birds. Environmental Toxicology and Chemistry 13 1303-1310.

Kallen CB, Arakane F, Christenson LK, Watari H, Devoto L \& Strauss III JF 1998 Unveiling the mechanism of action and regulation of the steroidogenic acute regulatory protein. Molecular and Cellular Endocrinology 145 39-45.

Kloas W, Reinecke M \& Hanke W 1994 Role of the atrial natriuretic peptide for adrenal regulation in the teleost fish Cyprinus carpio. American Journal of Physiology 267 R1034-R1042.

Leblond VS \& Hontela A 1999 Effects of in vitro exposures to cadmium, mercury, zinc, and 1-(2-chlorophenyl)-1-(4-chlorophenyl)-2,2dichloroethane on steroidogenesis by dispersed interrenal cells of rainbow trout (Oncorhynchus mykiss). Toxicology and Applied Pharmacology 157 16-22.

Leblond VS, Bisson M \& Hontela A 2001 Inhibition of cortisol secretion in dispersed head kidney cells of rainbow trout (Oncorhynchus mykiss) by endosulfan, an organochlorine pesticide. General and Comparative Endocrinology 121 48-56.

Lehoux JG, Fleury A \& Ducharme L 1998 The acute and chronic effects of adrenocorticotropin on the levels of messenger ribonucleic acid and protein of steroidogenic enzymes in rat adrenal in vivo. Endocrinology 139 3913-3922.

Lin D, Sugawara T, Strauss III JF, Clark BJ, Stocco DM, Saenger P, Rogol A \& Miller WL 1995 Role of steroidogenic acute regulatory protein in adrenal and gonadal steroidogenesis. Science $\mathbf{2 6 7}$ $1828-1830$

Lund BO 1994 In vitro adrenal bioactivation and effects on steroid metabolism of DDT, PCBs and their metabolites in the grey seal (Halichoerus grypus). Environmental Toxicology and Chemistry 13 911-917.

Mason JI \& Robidoux WF 1978 Pregnenolone biosynthesis in isolated cells of snell rat adrenocortical carcinoma 494. Molecular and Cellular Endocrinology 12 299-308.

Mason JI, Carr BR \& Rainey WE 1986 The action of phorbol ester on steroidogenesis in cultured human fetal adrenal cells. Endocrine Research 12 447-467.

Mgbonyebi OP, Smothers CT \& Mrotek JJ 1994 Modulation of adrenal cell functions by cadmium salts: 3 . Sites affected by $\mathrm{CdCl}_{2}$ during stimulated steroid synthesis. Cell Biology and Toxicology 10 35-43.

Miller WL 1988 Molecular biology of steroid hormone synthesis. Endocrine Reviews 9 295-318.

Naseeruddin SA \& Hornsby PJ 1990 Regulation of $11-\beta$ and $17-\alpha$-hydroxylases in cultured bovine adrenocortical cells: $3^{\prime}, 5^{\prime}$-cyclic adenosine monophosphate, insulin-like growth factor-I, and activators of protein kinase C. Endocrinology 127 1673-1681.

Patiño R, Bradford CS \& Shreck CB 1986 Adenylate cyclase activators and inhibitors, cyclic nucleotide analogs, and phosphatidylinositol: effects on interrenal function of coho salmon (Oncorhynchus kisutch) in vitro. General and Comparative Endocrinology $63230-235$.

Perrott MN \& Balment RJ 1990 The renin-angiotensin system and the regulation of plasma cortisol in the flounder, Platichus flesus. General and Comparative Endocrinology 78 414-420.

Pescador N, Houde A, Stocco DM \& Murphy BD 1997 Follicle-stimulating hormone and intracellular second messengers regulate steroidogenic acute regulatory protein messenger ribonucleic acid in luteinized porcine granulosa cells. Biology of Reproduction 57 660-668.

Privalle CT, Crivello JF \& Jefcoate CR 1983 Regulation of intramitochondrial cholesterol transfer to side-chain cleavage cytochrome P450 in rat adrenal gland. PNAS 80 702-706.

Schimmer BP 1995 The 1994 Upjohn Award Lecture. Molecular and genetic approaches to the study of signal transduction in the adrenal cortex. Canadian Journal of Physiology and Pharmacology $\mathbf{7 3}$ 1097-1107.

Srivastava RK \& Van Der Kraak G 1994a Effects of activators of different intracellular signaling pathways on steroid production by goldfish vitellogenic ovarian follicles. General and Comparative Endocrinology 93 181-191.

Srivastava RK \& Van Der Kraak G $1994 b$ Insulin as an amplifier of gonadotropin action on steroid production: mechanisms and sites of action in goldfish prematurational full-grown ovarian follicles. General and Comparative Endocrinology 95 60-70.

Stocco MD \& Clark BJ 1996 Regulation of the acute production of steroids in steroidogenic cells. Endocrine Reviews 17 221-244.

Toaff ME, Schleyer H \& Strauss III JF 1982 Metabolism of 25-hydroxycholesterol by rat luteal mitochondria and dipersed cells. Endocrinology 111 1785-1790.

Tuckey RC 1992 Cholesterol side-chain cleavage by mitochondria from the human placenta. Studies using hydroxycholesterols as substrates. Journal of Seroid Biochemistry and Molecular Biology 42 883-890.

Tuckey RC \& Atkinson HC 1989 Pregnenolone synthesis from cholesterol and hydroxycholesterols by mitochondria from ovaries following the stimulation of immature rats with pregnant mare's serum and human choriogonadotropin. European Journal of Biochemistry 186 255-259.

Tuckey RC \& Holland JW 1989 Comparison of pregnenolone synthesis by cytochrome $\mathrm{P}-450 \mathrm{scc}$ in mitochondria from porcine corpora lutea and granulosa cells of follicles. Journal of Biological Chemistry 264 5704-5709.

Van Der Kraak G 1990 The influence of calcium ionophore and activators of protein kinase $\mathrm{C}$ on steroid production by preovulatory ovarian follicles of the goldfish. Biology of Reproduction 42 231-238.

Van Der Kraak G 1992 Mechanisms by which calcium ionophore and phorbol ester modulate steroid production by goldfish preovulatory ovarian follicles. The Journal of Experimental Zoology 262 271-278.

Wendelaar Bonga SE 1993 Endocrinology. In The Physiology of Fishes, pp 140-180. Ed DH Evans. Boca Raton: CRC Press.

Wendelaar Bonga SE 1997 The stress response in fish. Physiological Reviews 77 591-625.

Widmaier E \& Hall P 1985 Protein kinase C in adrenal cells: possible role in regulation of steroid synthesis. Molecular and Cellular Endocrinology 43 181-188.

Yoshida T, Mio M \& Tasaka K $1993 \mathrm{Ca}^{2+}$-induced cortisol secretion from permeabilized bovine adrenocortical cells: the roles of calmodulin, protein kinase C and cyclic AMP. Pharmacology 46 181-192.

Received in final form 21 November 2000

Accepted 30 November 2000 